\title{
Antimicrobial activities of human biofluids and their antimicrobial peptide fractions against Candida albicans
}

\author{
Vera Arzumanian $^{1}$, Taisia Erofeeva ${ }^{1}$, Polina Zhigalkina ${ }^{2, *}$ and Oxana Svitich ${ }^{3}$ \\ ${ }^{1}$ Laboratory of Fungal and Bacterial Physiology, Mechnikov Research Institute for Vaccines and Sera; \\ ${ }^{2}$ Federal State Autonomous Educational Institution of Higher Education, I. M. Sechenov First Moscow \\ State Medical University of the Ministry of Health of the Russian Federation (Sechenov University); \\ ${ }^{3}$ Laboratory of Molecular Immunology, Mechnikov Research Institute for Vaccines and Sera, \\ Moscow, Russia.
}

\begin{abstract}
It is known that human biological fluids contain antimicrobial protective factors that include antimicrobial peptides (AMP). Concentrations of AMP vary in different biofluids and tissues. The aim of the present study is to estimate the total antimicrobial activity of different human biofluids in comparison with the activity of their AMP fractions as markers of local immunity. The antimicrobial activities of serum (SE), vaginal fluid (VF), saliva (SA), water-soluble part of skin secretion (SS) and urine (UR) of 6 healthy women, 22-25 years old, were measured by the spectrophotometric method based on the ability of the above-mentioned biofluids to disrupt the cytoplasmic membrane of Candida albicans [Patent RF № 2602298]. The results were evaluated as the percent of dye penetrated into dead cells of treated yeast cell suspensions compared to the control ones. The medians of total and AMP activities are SE - 86.6\% and $33.7 \%$; VF $-24.8 \%$ and $21.9 \%$; SA $-18.3 \%$ and 10.9\%; SS $-12.8 \%$ and $2.8 \%$; UR $-10.0 \%$ and $0.0 \%$, respectively. The highest level of immune defense occurs in SA whereas the lowest in UR. The antimicrobial activity of AMP in VF is maximal compared to the other biofluids. Levels of total and AMP activities of SA, SS and UR
\end{abstract}

*Corresponding author: polinkav_95@mail.ru have high positive correlation between each other (Pirson's correlation coefficients $r \geq 0,700$ ), while none of them correlated with the activities of VF $(r \leq 0,300)$. Using the most appropriate method of antimicrobial activity estimation the differences between biofluids of healthy human tissues of different localization are demonstrated for the first time.

KEYWORDS: antimicrobial peptides, human biofluids, Candida albicans.

\begin{tabular}{lll}
\multicolumn{2}{l}{ ABBREVIATIONS } \\
A & $:$ & activity of specimen, $\%$ \\
AMP & $:$ & antimicrobial peptides \\
OD $_{\text {control }}$ & $:$ & $\begin{array}{l}\text { optical density of control } \\
\text { supernatant }\end{array}$ \\
OD $_{\text {exp }}$ & $:$ & $\begin{array}{l}\text { optical density of experimental } \\
\text { Supernatant }\end{array}$ \\
SA & $:$ & saliva \\
SE & $:$ & serum \\
UR & $:$ & urine \\
VF & $:$ & vaginal fluid
\end{tabular}

\section{INTRODUCTION}

Human biofluids contain immune defense factors such as complement proteins (CP), immunoglobulins (Ig) and antimicrobial peptides (AMP), all of them having a direct antimicrobial effect. While $\mathrm{CP}$ occur only in serum, Ig and AMP are found in 
serum and in all secretions of human body, for example vaginal and skin secretions, saliva, urine etc. [1-5]. The most common AMP include defensins, cathelicidins, secretory inhibitor of leucoprotease, lactoferrin, lysozyme, psoriasin, dermcidins, ribonuclease 7 , calprotectin, histatin, hepcidin and lipocalin. Most of the CP and all Ig have a molecular mass above $150 \mathrm{kDa}$, but AMP are the family comprising of more than 20 peptide nature substances with mass up to $80 \mathrm{kDa}$. Concentrations of AMP vary in different biofluids and tissues. Recently we developed a useful method for estimating the AMP fraction activity in different human secretions [6]. The aim of the present study is the evaluation of total antimicrobial activity in different human biofluids in comparison with the activity of their AMP fractions as markers of local immunity, and estimation of a possible concordance of these parameters in different individuals.

\section{MATERIALS AND METHODS}

Volunteers for all experiments include 6 healthy women, 20-26 years old. Biofluids such as serum (SE), saliva (SA), urine (UR), vaginal fluid (VF) and water soluble part of skin secretion (SS) were investigated. All specimens were harvested in the morning prior to breakfast and any washing procedures except for SA which was obtained after tooth brushing and oral rinsing by water. Collection of VF was carried out by the following method: a tampon (OB Pro comfort) was inserted into the vagina for 10 minutes, and then the tampon was transferred to a plastic column of $15 \times 75 \mathrm{~mm}$ and eluted with $7 \mathrm{ml}$ of distilled water using a vacuum pump. Specimens of SS were collected from upper back skin site of $6 \mathrm{~cm}^{2}$ as follows: a glass ring of $1 \mathrm{~cm}$ height and $24 \mathrm{~cm}$ diameter was placed on the skin, and the ring was filled with $3 \mathrm{ml}$ of sterile distilled water. The skin inside the ring was intensively rubbed with plastic stick and the SS was collected along with the water. Every specimen from the different sites was filtered through the membrane filter Millipore having a pore diameter of $0.22 \mu$, freezed at $-25^{\circ} \mathrm{C}$ and then thawed out before the experiment, centrifuged for $5 \mathrm{~min}$ at $16000 \mathrm{rpm}$ and the supernatant prior to the filtration was used for the further procedures (fraction "Total”) or filtered through a membrane of $100 \mathrm{kDa}$ («Amicon ultra», Germany) (fraction “AMP”).

Yeast strains used for all experiments were selected from the laboratory collection - Candida albicans № 927. Cultivation of yeast was carried out in Petri dishes with solid Sabouraund medium supplemented with antibiotics at $25^{\circ} \mathrm{C}$ for 19 hours.

Estimation of antimicrobial activity was carried out by the following procedure: $50 \mu \mathrm{l}$ suspension of test-culture C. albicans № 927 (final concentration of cells about $10^{8} \mathrm{CFU} / \mathrm{ml}$ ) was combined with $400 \mu \mathrm{l}$ of specimen in an Eppendorf tube. Control sample contained $400 \mu \mathrm{l}$ of normal saline solution instead of the analyzed specimen. The mixture was incubated on a shaker at $32{ }^{\circ} \mathrm{C}$ for 2 hours, and after that centrifuged for 5 mins at $16000 \mathrm{rpm}$; the supernatant was removed and $300 \mu \mathrm{l}$ of the dye $2 \mathrm{mM}$ bromocresol purple in $1.25 \mathrm{M}$ phosphate buffer ( $\mathrm{pH} 4.6$ ) was added and incubated again for 45 mins. After centrifugation $50 \mu \mathrm{l}$ of the supernatant was dissolved in $2.5 \mathrm{ml}$ of the same buffer and the optical density was measured at a wavelength of $440 \mathrm{~nm}$ using a spectrophotometer ("Genesys $10 \mathrm{~S}$ UV-Vis”, USA). These procedures were carried out three times.

The antimicrobial activity was calculated according to [7] using the following formula:

$\mathrm{A}=\left(\mathrm{OD}_{\text {control }}-\mathrm{OD}_{\text {exp }}\right) * 100 / \mathrm{OD}_{\text {control }}$

A - activity of specimen, \%;

$\mathrm{OD}_{\text {control }}$ - optical density of control supernatant;

$\mathrm{OD}_{\exp }$ - optical density of experimental supernatant.

Statistical evaluation of obtained results was carried out by parametric and nonparametric methods of 'MS Excel', and 'Statistica for Windows'.

\section{RESULTS}

The method of estimation of antimicrobial activity is based on the ability of CP, Ig and AMP to destroy the cytoplasmic membrane. As a result of such destruction the dye - bromocrezol purple inserts into the damaged Candida cells and its concentration in the incubation medium decreases. The control specimen of test-culture, in which majority of cells (70-80\%) are alive, absorbs less 
amount of dye than the experimental specimen, and hence the optical density in the control supernatant is always higher than that in the experimental one. The results of investigation of the activities of the different biofluids against C. albicans are presented in Table 1 and Figures 1 and 2.

Based on the obtained data one can see that SE demonstrated the maximal candidacidal effect compared to other biofluids in total fraction as well as in AMP fraction. However, unlike VF and SS, SE, SA and UR are native liquids because of the methods of their collection, whereas methods of VF and SS collection include the stage of elution (VF) or washing (SS) by distilled water. Therefore these biofluids become diluted compared to the natural secretions. Nevertheless SE is the most active among native liquids.

Comparison of the average values of the obtained parameters allows to estimate the percent of AMP activity in total activity against $C$. albicans (Table 1). Clearly, the maximal contribution of AMP is found in VF, and the minimal in UR. Medians of the parameters show even more impressive data (Figure 2): contribution of AMP in total activity of UR is equal to zero. Correlations between antimicrobial activities of different biofluids from 6 healthy volunteers are shown in Table 2. Levels of total activities of SS, UR and SA have high positive correlation between each other ( $r \geq 0,700)$, while none of them correlated with the activities of VF $(r \leq 0,300)$. The same situation occurs with AMP activities.

\section{DISCUSSION}

Antimicrobial activities of five human biofluids, including activities of their AMP fractions, against $C$. albicans were investigated for the first time. Traditionally studied AMP are defensins, cathelicidins, secretory inhibitor of leucoprotease, lactoferrin, lysozyme, psoriasin, dermcidins, ribonuclease 7 , calprotectin, histatin, hepcidin, and lipocalin. Some of the AMP occurred in all the mentioned biofluids: these are defensins, cathelicidins, secretory inhibitor of leucoprotease, lactoferrin, lysozyme, psoriasin, and lipocalin. Besides, the average concentrations of the prevailing AMP in the different biofluids are as follows:

- for SE - lysozyme - about $3 \mu \mathrm{g} / \mathrm{ml}$ [8] and calprotectin - $3 \mu \mathrm{g} / \mathrm{ml}$ [9];

- for VF - lysozyme - $13 \mu \mathrm{g} / \mathrm{ml}$, lactoferrin $8 \mu \mathrm{g} / \mathrm{ml}$ and calprotectin - $34 \mu \mathrm{g} / \mathrm{ml} \mathrm{[10];}$

- for SA - defensin h $\beta \mathrm{D}-1$ - $10 \mu \mathrm{g} / \mathrm{ml}[11]$, secretory inhibitor of leucoprotease - $18 \mu \mathrm{g} / \mathrm{ml}$ [12], lactoferrin - $8 \mu \mathrm{g} / \mathrm{ml}$ [13], lysozyme $4 \mu \mathrm{g} / \mathrm{ml}$ [14], psoriasin - $14 \mu \mathrm{g} / \mathrm{ml} \mathrm{[15]} \mathrm{and}$ histatin - $33 \mu \mathrm{g} / \mathrm{ml}[16]$;

- for SS - dermcidins - $6 \mu \mathrm{g} / \mathrm{ml}$ [17] (information about concentrations of other SS AMP was not found);

- $\quad$ for UR - RNAse 7 - $2 \mu \mathrm{g} / \mathrm{ml}[18]$.

According to the type and concentrations of AMP the maximal activity should be expected in SA, although the most active undiluted biofluid (and its AMP fraction) is SE. However the minimal

Table 1. Candidacidal activities of different biofluids from 6 healthy volunteers.

\begin{tabular}{|c|c|c|c|c|}
\hline \multirow{2}{*}{ Biofluids } & \multicolumn{2}{|c|}{ Antimicrobial activity, \% } & \multirow{2}{*}{$\begin{array}{c}\text { Significance level of } \\
\text { differences between } \\
\text { total and } 100 \mathrm{kDa} \\
\text { activities }\end{array}$} & \multirow{2}{*}{$\begin{array}{c}\text { Percent of AMP } \\
\text { activity compared } \\
\text { to total activity, } \\
\%\end{array}$} \\
\hline & Total & AMP & & \\
\hline Serum & $86.9 \pm 1.3$ & $38.3 \pm 6.8$ & $\mathrm{p} \leq 0.01$ & 44.1 \\
\hline Vaginal fluid & $24.8 \pm 8.3$ & $20.8 \pm 3.5$ & $\mathrm{p}>0.05$ & 83.9 \\
\hline Saliva & $21.3 \pm 8.1$ & $10.9 \pm 5.8$ & $\mathrm{p}>0.05$ & 51.2 \\
\hline $\begin{array}{l}\text { Water soluble part } \\
\text { of skin secretion }\end{array}$ & $14.0 \pm 4.9$ & $5.7 \pm 5.4$ & $0.01 \leq \mathrm{p} \leq 0.05$ & 40.7 \\
\hline Urine & $10.2 \pm 6.4$ & $1.5 \pm 2.2$ & $0.01 \leq \mathrm{p} \leq 0.05$ & 14.7 \\
\hline
\end{tabular}




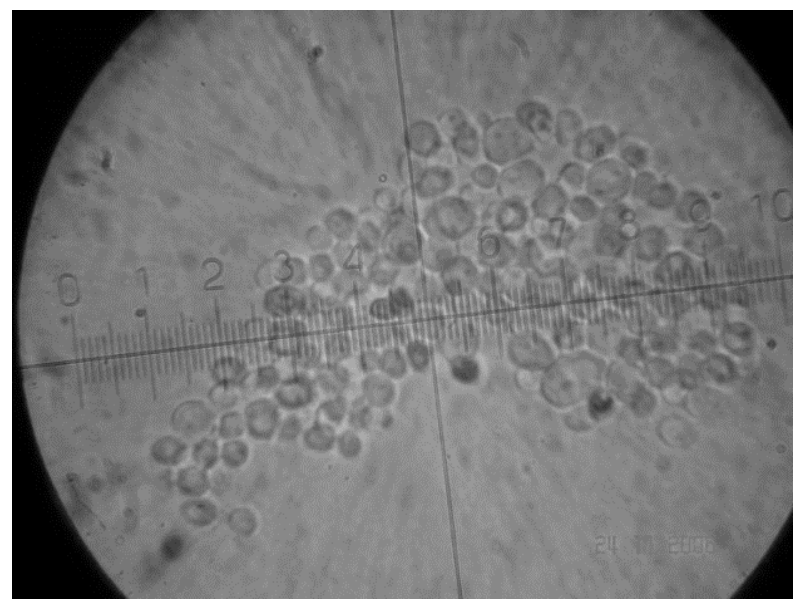

A

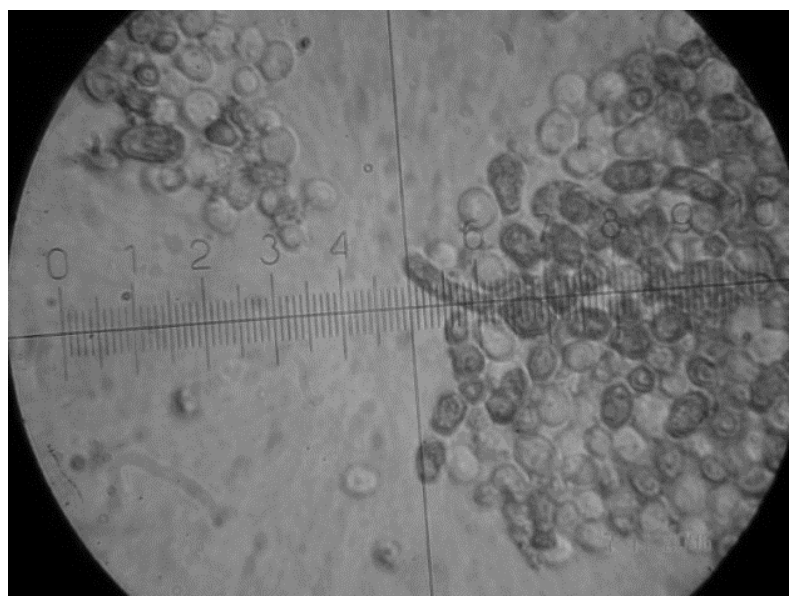

B

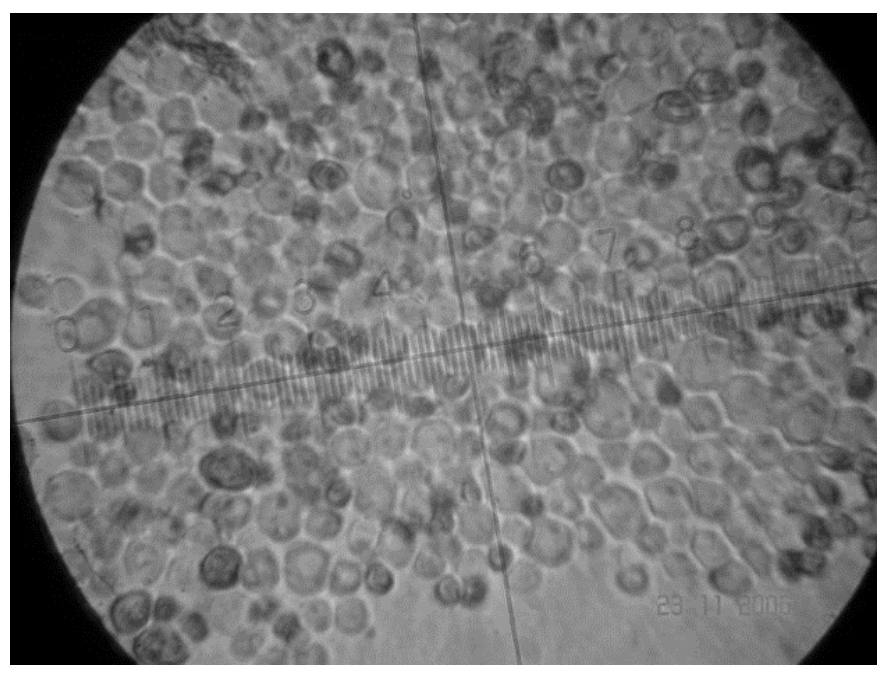

C

Figure 1. Effect of different saliva fractions on Candida albicans cells. A - control specimen; B - total saliva; $\mathbf{C}$ - the AMP fraction ( $<100 \mathrm{kDa})$ of saliva.

known concentrations of AMP as well as the minimal estimated AMP activities occurred in SS and UR. The overall AMP activity apparently is not the simple sum of their individual activities.

Very intriguing is the fact that the role of AMP is varied in each biofluid. AMP fraction estimated as the percentage of AMP activity compared to the total activity decreases in the following sequence: VF-SA-SE-SS-UR. Therefore the antimicrobial defense of vagina is provided mainly by AMP, whilst urinary AMP do not play significant role in this locus.

The reason for high correlations between antimicrobial activities of UR-SS-SA (and low correlations with activities of VF) could be attributed to common embryogenesis of the tissues which secrete each of these biofluids. However it is well known that AMP:

- of SE are produced by neutrophils originating from mesoderm; 
- of VF - by cells of vaginal epithelium - from ectoderm;

- of SA - by salivary glands - from endoderm;

- of SS - by epidermal sweat glands - from ectoderm;
- of UR - by epithelium of urinary bladder (endoderm) and kidneys (mesoderm).

From the above it is obvious that this hypothesis of correlation between UR-SS-SA does not have enough confirmation.

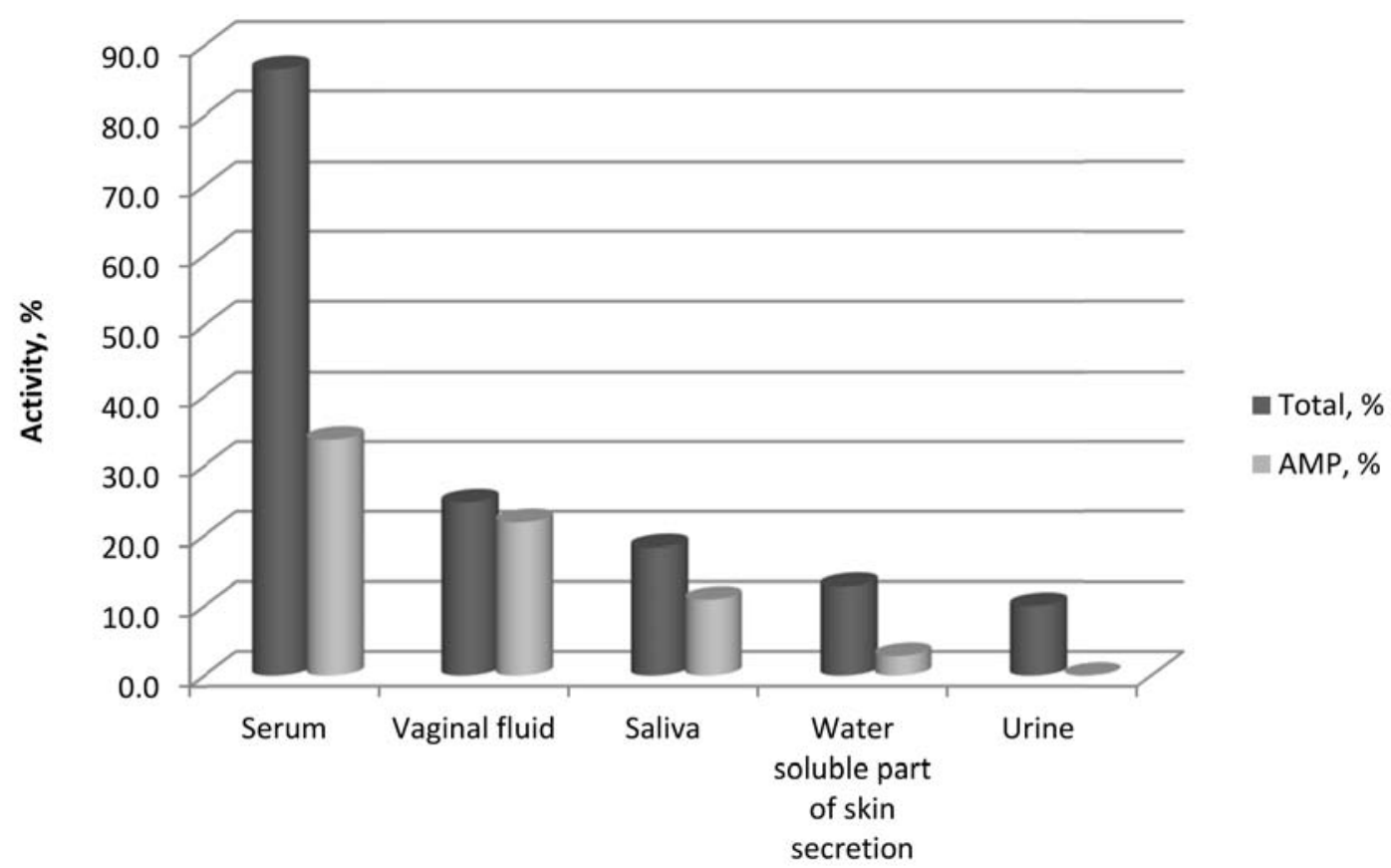

Figure 2. Medians of candidacidal activities of different biofluids from 6 healthy volunteers.

Table 2. Correlations between antimicrobial activities of different biofluids from 6 healthy volunteers.

\begin{tabular}{|l|c|c|}
\hline \multirow{2}{*}{\multicolumn{1}{|c|}{ Compared bioliqids }} & \multicolumn{2}{c|}{ Pirson's correlation coefficients } \\
\cline { 2 - 3 } & Total antimicrobial activities & AMP activities \\
\hline $\begin{array}{l}\text { Vaginal fluid - Water soluble part of skin } \\
\text { secretion }\end{array}$ & -0.517 & -0.348 \\
\hline Vaginal fluid - Urine & -0.579 & -0.068 \\
\hline Vaginal fluid - Serum & -0.490 & -0.015 \\
\hline Vaginal fluid - Saliva & -0.692 & 0.055 \\
\hline Serum - Urine & 0.530 & 0.081 \\
\hline Serum - Water soluble part of skin secretion & 0.195 & 0.439 \\
\hline Serum - Saliva & 0.343 & 0.563 \\
\hline Saliva - Urine & 0.897 & 0.571 \\
\hline Saliva - Water soluble part of skin secretion & 0.713 & 0.689 \\
\hline Urine - Water soluble part of skin secretion & 0.846 & 0.814 \\
\hline
\end{tabular}




\section{CONCLUSION}

On the basis of the obtained experimental data one can conclude that SE is the most active human liquid against the yeast $C$. albicans, but the maximal activity of AMP fraction in comparison with the total activity was noted in VF. Values of total and AMP activities of SA, SS and UR have high positive correlation between each other, while none of them correlated with the activities of VF. Using the most appropriate method of antimicrobial activity estimation the differences between biofluids of healthy human tissues of different localization were demonstrated for the first time. Anyway the investigated parameters may be significant in the diagnostics of human epithelial tissue immunity. Further investigation would need additional groups of volunteers/ patients and test cultures of otherpportunistic microorganisms.

\section{ACKNOWLEDGEMENT}

The authors express their thanks to Tamara Artemieva and Liubov Butovchenko for technical support and permanent care.

\section{CONFLICT OF INTEREST STATEMENT}

The authors of this publication have research support from Mechnikov Research Institute for Vaccines and Sera (Moscow, Russia) and also conduct research in areas of interest similar to the business interests of Mechnikov Research Institute for Vaccines and Sera. We have no conflicts of interest to disclose.

\section{REFERENCES}

1. Levy, O. 2000, Blood, 96, 2664.

2. Dale, B. A. and Fredericks, L. P. 2005, Curr. Issues Mol. Biol., 7, 119.

3. Arzumanian, V., Malbakhova, E. and Vartanova, N. 2012, A Search for Antibacterial Agents, V. Bobbarala (Ed.), InTech, Croatia, 125.
4. Arzumanian, V. and Kabaeva, T. 2008, Experimental'naya i klinicheskaya dermatokosmetologia (Russ.), 3, 47.

5. Nienhouse, V. 2012, Master's Theses, Univ. of Chicago, 727.

6. Arzumanian, V., Malbakhova, E., Foshina, E., Artemeva, T., Butovchenko, L., Vartanova, N. and Shmeleva, O. 2015, Patent RF № 2015113069/15.

7. Arzumanian, V., Shmeleva, O. and Michailova, N. 2017, Med. Mycol. Open Access, 3, 23.

8. Johansson, B. and Malmquist, J. 1971, Scandinavian Journal of Clinical and Laboratory Investigation, 27, 255.

9. Meuwis, M., Vernier-Massouille, G., Grimaud, J., Bouhnik, Y., Laharie, D., Piver, E., Seidel, L., Colombel, J. and Louis, E. 2013, J. Crohns Colitis, 7, 678.

10. Valore, E., Park, C., Igreti, S. and Ganz, T. 2002, J. Obstet. Gynecol., 187, 561.

11. Kucukkolbasi, H., Kucukkolbasi, S., Ayyildiz, H. F. and Dursun, R. 2013, West Indian Med. J., 62, 58.

12. Wahl, S., McNeely, T., Janoff, E., Shugars, D., Worley, P., Tucker, C. and Orenstein, J. 1997, Oral Dis., 1S, 64.

13. Berlutti, F., Pilloni, A., Pietropaoli, M. and Polimeni, A. 2011, Curr. Issues Mol. Biol., 7, 119 .

14. Jenzano, J., Hogan, S. and Lundblad, R. 1986, J. Clin. Microbiol., 24, 963.

15. Giusti, L., Sernissi, F., Donadio, E., Ciregia, F., Giacomelli, C., Giannaccini, G., Mazzoni, M. R., Lucacchini, A. and Bazzichi, L. 2016, J. Transl. Med., 14, 262.

16. Tsai, H. and Bobek, L. 1998, Crit. Rev. Oral Biol. Med., 9, 480.

17. Rieg, S., Steffen, H., Seeber, S., Humeny, A. Kalbacher, H., Dietz, K., Garbe, C. and Schittek, B. 2005, J. Immunol., 174, 8003.

18. Spencer, J., Schwaderer, A., Dirosario, J. and McHugh, K. 2011, Kidney International, 80, 174. 